\title{
Direct prediction of isotopic properties from molecular dynamics trajectories: Application to sulfur radical species
}

MARC BLANCHARD ${ }^{1}$, RODOLPHE VUILLEUMIER ${ }^{2}$, ELSA DESMAELE ${ }^{2}$ AND GLEB S. POKROVSKI ${ }^{1}$

${ }^{1}$ Géosciences Environnement Toulouse - CNRS - Univ Toulouse III - IRD - CNES - OMP

${ }^{2}$ Ecole normale supérieure - CNRS

Presenting Author: marc.blanchard@get.omp.eu

Sulfur isotope fractionations have been used for tracing various geological processes since 1960's. In hydrothermal fluids, aside from the major chemical forms of sulfur that are known to be sulfate and sulfide, "new" species, such as $\mathrm{S}_{2}{ }^{-}$and $\mathrm{S}_{3}{ }^{--}$radical ions, have been discovered [1], with potentially significant consequences on the formation of ore deposits. However, the isotopic properties of these radical species are poorly known $[2,3]$. In complement to experimental studies, atomistic modeling now offers quantitative tools for investigating isotope fractionation, even though the accurate prediction of such isotopic properties is yet challenging for fluids due to their dynamical and anharmonic behavior. In the present work, we employ first-principles molecular dynamics (MD) to model the four key sulfur-bearing species $\left(\mathrm{S}_{2}{ }^{-}, \mathrm{S}_{3}{ }^{--}, \mathrm{SO}_{4}{ }^{2-}, \mathrm{H}_{2} \mathrm{~S}\right)$ in hydrothermal conditions. Equilibrium isotope fractionation is calculated directly from the MD trajectories by using the atomic kinetic energy. Results are compared with the more traditional method based on the sampling of several snapshots along the MD trajectories and also with the available experimental isotope fractionations. This work provides the isotopic signatures of the sulfur radical species and allows their comparison with those of the traditional sulfate and sulfide.

[1] Pokrovski, G.S. \& Dubrovinsky, L.S. (2011), Science 331, 1052-1054.

[2] Tossell J.A. (2012), Geochim. Cosmochim. Acta 95, 7992.

[3] Kokh M.A., Assayag N., Mounic S., Cartigny P., Gurenko A. \& Pokrovski G.S. (2020), Geochim. Cosmochim. Acta 285, 100-128. 